\title{
Más allá de la metáfora
}

La poesía a través de los siglos ha sido cuestionada en razón de su objetivo. Lo cierto es que las artes responden a su momento cultural. Pero el verdadero problema está en que la poesia siempre ha sido considerada como un medio contemplativo del poeta y éste al igual que el pintor simplemente imita la realidad, pasivamente. De aceptar este razonamiento, diriamos, convencidos, que la poesía es una evasión de la realidad; un alejamiento de las tensiones del mundo. Sin embargo, no todos los poetas deben ser enjuiciados bajo estos principios inquisidores.

La poesía es y ha sido arte de gran estima y respeto, una labor noble para grandes hombres que han llenado páginas de la historia con su quehacer poético. Actualmente en nuestra sociedad existe una tendencia a medirlo todo con el rasero de lo social-político, y el móvil de este sustrato social y político es en definitiva lo económico, por lo tanto, la moral predeterminista en nuestra sociedad es la siguiente: todo es bueno, si es útil, y lo bueno y útil a la vez produce ganancia.

Existe un prurito absurdo a encauzarlo todo a un activismo desesperante. Ya no se trata de transformar el mundo y convertirlo en posibilidad de vida, sino de producir ciegamente, fragmentando la conciencia del hombre para que responda a las oleadas económicas que le impone la sociedad de consumo y la demanda.

En una sociedad como la nuestra las artes pierden interés y el hombre es reducido a sus instintos elementales: comer, vestir, procrear y esto equivale a consumir. Por lo tanto, el hombre de hoy es la suma de resultados experimentales. Se tiende a lo contingente, a lo fugaz, expectante, pero no necesario, ni de acuerdo a la significación interna de su naturaleza humana. En otras palabras, el hombre se ha resignado a vivir bajo una aceptación disminuida de la vida.

Con nuestra reflexión no pretendemos agotar un tema, pero si reivindicar la labor artística del poeta y plantearnos más o menos el siguiente esquema: el poeta está incorporado a su propia estructura social y desde ella habla a los hombres de su tiempo, utiliza la palabra que también es producto social y medio de cultura. Las palabras no son signos pasivos, tienen un significado y encierran un mundo de interrelacio- 
nes, donde el poeta toma conciencia activa y se interroga para escribir no desde fuera, sino desde dentro. Cada poeta tiene su estilo y la forma está delimitada por el ritmo de su tiempo. La poesía es una novedad continua, no pasa; los poetas mueren y la poesía es para siempre.

\section{Palabra y silencio}

Todo lenguaje exige siempre una reflexión. Cuando escuchamos a una persona que está tratando de comunicarse, todo nuestro ser se activa: el conocimiento ordena las ideas, el oído escucha atentamente, la vista observa cada forma en que es articulada cada palabra. Hay todo un proceso desencadenado y es urgente dar coherencia a todas las ideas. Almacenamos los datos necesarios, clasificándolos dentro del espacio y el tiempo, hasta ponerlos al alcance del hombre común, es decir, que todo término dentro de la comunicación debe ser percibido claro e inequivocamente. Cada palabra posee un sonido que es elemental dentro de un sistema fonético. La palabra tiene una representación ideal. No es un sonido vacio que se desvanece eternamente. La palabra es un acontecimiento y a la vez es única en cada ocasión en que se pronuncia.

El poeta pronuncia palabras y además las escribe a través de signos que nos revelan siempre una realidad o, por lo menos, hace referencia a ella.

El mundo es más que la palabra sola, es un continuo devenir, donde el hombre tiene que tener conciencia de su propio destino. Frente al mundo el hombre es toda sensación, cada parte de su cuerpo percibe el entorno que le circunda.

Todas las cosas tratan de comunicarnos algo, poseen vida, calor, musicalidad, movimiento. El mundo es un manantial de vida donde el hombre irrumpe como amo y señor, extiende sus dominios y las fronteras no tienen limites. El hombre también es infinito. Pertenece al juego de la vida donde se conjuga la alegria y el dolor, la luz y las tinieblas, pasión, vida y muerte. Esto es poesía y el hombre se integra al mundo no como un extraño, sabe perfectamente que su casa ha sido siempre el mundo, y las cosas han estado ahí siempre comunicándose, en una relación mutua, hombre y mundo.

La palabra es para el hombre el vehículo esencial, indispensable, y el mundo habla a través del hombre y éste se pone a su servicio, ofrece su mente, sus brazos, sus manos, su voz, todo el hombre es un sentimiento puro a través del cual y por el cual la naturaleza, el mundo de las cosas se comunican.

El hombre y el mundo es la combinación perfecta, el uno para el otro, integrados para ofrecer el mejor de los ángulos, la mejor perspectiva para comprender lo que no se entienda. Sin embargo, hombre y mundo conservan su propia identidad, cada uno es la parte de un todo, y por lo tanto, hombre y mundo son siempre un principio y no un ocaso.

El mundo se nos revela dinámicamente; en él existen acumulaciones de fuerzas capaces de hacer cambios radicales y profundos. 
El mundo es un devenir dentro del tiempo y de la historia y en ese movimiento continuo el hombre toma posesión del mundo, pero sin poseerlo todo. Es imposible que el hombre como sujeto pensante sea la totalidad de lo que es y de lo que ha de venir, teoría y práctica a la vez hacen al hombre un ser distinto pero no completo.

Siempre habrá nuevas expresiones y todo dentro del mundo es atravesado por el meridiano de las posibilidades.

Las cosas en el mundo nos hablan y el hombre como un ser comunicativo por excelencia debe hacer un alto, guardar la distancia adecuada, lejos del ruido que entorpece la comunicación, debe hacerse silencio, es la hora en que el mundo y las cosas que lo habitan, toman la palabra y nos dicen que están ahí, que poseen un valor y hasta lo más insignificante, lo más repugnante para nuestro gusto estético, tiene un verdadero sentido.

Habíamos dicho que en el mundo existen fuerzas activas y otras quizás latentes, pues bien, estas fuerzas están dispuestas a abrirnos a nuevos horizontes. Cada fenómeno aporta un verdadero destino. Por lo tanto, la palabra y el poeta y el silencio es la mejor manera para dar a conocer el mundo de las cosas. A través de la palabra el poeta interpreta el manantial de vida que nos ofrece generosamente la naturaleza. Cada palabra es savia en movimiento, es calor que da vida. Todo el sistema nervioso humano genera poesía que se renueva

La forma no debe ser un obstáculo para crear poesia, más bien debe ser el cauce por donde fluye el río de imágenes, alegorías. Es la vida misma un torrente de imaginación. Sin tiranizar la palabra que nos revela el mundo de las cosas, debemos usar cada término con amplitud de margen. La técnica, la armonía y el ritmo darán el toque mágico para que la palabra no sea un mero instrumento seco, frío, inerte. Todo lo contrario, el poeta, la palabra, las cosas tienen que tener color y deben ofrecer signos vitales que nos expresen que hay vida, que es posible la vida. Por lo tanto, es un objetivo ineludible, el salir de la oscuridad que enmascara el mundo de las cosas. Sin embargo, el poner al descubierto el mundo no significa llevar a cabo una transformación imaginaria de todo lo que existe, ni se trata de conmover al hombre a través de una sensibilización de un mundo inexistente. La metáfora no es una oscuridad simbólica, no es un mundo vacío, insustancial.

Los poetas no navegan en el vacio, ni aportan imágenes incoherentes al subconsciente humano. Nadie sufre de culpabilidad por no ser el mundo como otros quisieran que debería ser. Dentro de la realidad de cada cosa existe un mundo diferente y para captar la vida que encierra hay que detenerse, no hay que pasar desapercibido ante un hecho que merece nuestra atención, y éste lo es la vida misma cuantificada en múltiples dimensiones.

Las cosas nos hablan, nos interrogan progresivamente. Hay que detenerse. El hombre debe aprender a escuchar el sonido del viento, debe obsêrvar el sol de una media tarde, la lluvia, la piedra que está en el camino, la hoja que cruje a nuestro paso, escuchar la melodía de un pájaro 
furtivo, todo lo que acontece a nuestro derredor es lenguaje y posee un valor simbólico que se transforma en palabra. Por lo tanto, podemos decir con cierta determinación que el hombre en el mundo de las cosas se trata de comprender a sí mismo y el mundo no es ni será el mundo de las cosas que simplemente existen.

En el mundo el hombre tiene conciencia de su propio destino y aunque el camino de la vida no está libre de tropiezos y de sombras, es posible expresar lo que se siente y también, por qué no, lo que otros sienten y que a veces les es difícil expresar. Como el dolor, la angustia, el fracaso, el triunfo, la agonia. la muerte.

Es el poeta un hombre del silencio; sólo en la calma es posible tomar distancia en el mundo. Hacer silencio es reivindicarnos en el mundo de las cosas, pero también lo es el abrirnos caminos a través de un orden establecido que subordina la conciencia del hombre a fuerzas autoritarias.

En la sociedad actual se nos brinda una cosificación del mundo donde el hombre pierde su identidad y se deshumaniza; se pierde la armonía entre el mundo y el hombre y sobreviene el caos, las tinieblas, el desequilibrio mortal, hasta llegar al suicidio. El mundo se vuelve enemigo del hombre y éste impone las reglas de su juego, que se traduce en una norma muy simple: el mundo es causa del dolor, por lo tanto, si lo dominamos autoritariamente seremos felices.

Esta es la equivocación más grande, la angustia y el sentimiento de culpabilidad es un padecimiento psiquico, un desequilibrio en el mismo hombre. Destruyendo el mundo de las cosas, el hombre se destruye a sí mismo. Asegura su propia tumba, simplemente hay que atravesar el umbral que separa la vida de la muerte.

Es la poesia un elemento vital dentro de lo cotidiano del mundo. Los hombres hacen poesía en cada gesto, en cada acción donde se desencadenan los sentimientos humanos. Sobreviene el silencio y el hombre y las cosas se ubican dentro de una realidad, única y total. Aqui debemos anotar lo siguiente: el mundo de las cosas es un ambiente de veracidad, todo es positivo en él. De tal forma que el hombre hace de cada cosa un objeto de su observación. Todo lo penetra con su yo.

El poeta busca situarse dentro del tiempo y el espacio. El mundo de las cosas se ve invadido, influenciado por el estado animico del poeta; la intimidad del mundo de las cosas dejan de ser un secreto para sí mismo $y$ se nos ofrecen sin egoísmo, sin limite alguno. El hombre-poeta se vuelve portavoz de su hallazgo y el mundo de las cosas y el poeta se proyectan en una creación mágica de conceptos, metáforas que se mueven velozmente, ofreciendo a la vez una condensación de toda una realidad. Es decir, el poeta en su poesia trata de unificar una serie de circunstancias que dan sentido a la realidad, haciendo posible que la persona que guste de leer poesía se sensibilice a través del lenguaje que ofrece la poesía. Un mundo de metáforas que ofrecen algo más de lo que uno piensa y de lo que está escrito.

El poeta frente al mundo de las cosas logra un intercambio conti- 
nuo entre palabra-realidad. Las cosas pueden ser el árbol que ofrece su pálida sombra; la piedra que yace quieta en el silencio, la yerba suave y verde, la casa, vacía y solitaria. Es el mundo de las cosas no la materia fría con la cual la mente humana juega y transforma en números y planos que delimitan el dominio absoluto donde el hombre se siente amo y juez. Es imposible establecer un equilibrio, un lugar de entendimiento, si el hombre no toma conciencia de que la humanidad somos nosotros, cada ser humano que ocupa un espacio real donde el mundo es uno solo con el hombre. Uno y eterno presente, el poeta y el mundo de las cosas. Una vision totalizadora, donde el mundo de las cosas tiene un vehículo que el hombre le ofrece: la palabra y esta palabra ordenada artísticamente es poesía, silencio relativo, donde el poeta se ha sensibilizado, percibiendo el lenguaje de las cosas no como un mundo estático, diferenciado del hombre, sino como un mundo de infinitas posibilidades.

Sin perder de vista el significado de las cosas, el poeta utiliza a éstas en una serie de circunstancias que conforman un entorno poético. No es que el poeta refleje simplemente su estado animico, o trate de satisfacer una necesidad biológica-histórica para consagrar en un poema un determinado suceso que ha impactado al mundo. No, este sería algo absurdo, porque el poeta comunica la realidad en toda su desnudez y la poesia es más bella cuando se nos presenta ausente de retórica, de todo obstáculo que ensombrece la expresión viva del poema.

La palabra es la encarnación de todo lo que apasiona al hombre, se acaricia en la mente el concepto nuevo con el cual tratamos de definir el ser de las cosas. Las palabras no brotan de la nada, y esto cualquiera lo entiende, por lo tanto cada palabra tiene un respaldo real; en cada palabra que pronunciamos surge una realidad por medio de la cual el hombre toma conciencia de su destino. En cada situación el hombre tiene que definirse. No puede permanecer impasible.

Hay que tener en cuenta que la realidad es y también es un poco más, digo un poco más, pues, es muy simple. Las cosas no se agotan al ser conceptualizadas, el mundo de las cosas es siempre un ángulo en proyección, un estar comenzando, nunca un final.

Palabra y silencio hacen al poeta, y la poesia sólo tiene vida y significado en el mundo de las cosas, donde el hombre es sensible en toda la extensión de su ser. Hasta una simple brisa es inspiración para lograr percibir un entorno, el pequeño mundo que el poeta crea a través de su palabra.

\section{Poesía y poetas}

En el mundo de las cosas el poeta no puede permanecer en un total silencio. Cualquier circunstancia por muy trivial que parezca no puede pasar inadvertida ante el ojo visor del poeta. Un barco que navega sin rumbo definido, una mujer que deslumbra por su mirada tierna, una gota de rocío sobre el desnudo pétalo que duerme; la muerte que inunda con sus sombras y el hombre y las montañas, las estrellas, el universo tan 
extenso, pero relativamente comprensible; la ciudad con sus calles vacías, la noche y el silencio extremo, etcétera. Todo es objeto para la poesía y el poeta al tomar su pluma y al deslizarla sobre una impecable hoja blanca, siente recorrer en su torrente sanguíneo todo un mundo de ideas y de armonias convertidas en metáforas, que poseen vida propia. Asi es la poesia y así es el mundo del poeta.

La poesia está cerca de cada hombre, es la realidad cotidiana y el poeta la convierte en lenguaje poético, por medio del cual nos evoca recuerdos: el amigo, la noche de un amor, la alegria y hasta el dolor mismo. La poesía nos descubre el mundo de las cosas, nos enseña a amarlo en toda su belleza y esplendor. La naturaleza nos habla, el mundo de las cosas nos habla y el hombre percibe este lenguaje y acorta las distancias. En el mundo el hombre efectúa un diálogo continuo y logra una coexistencia dinámica donde se descubren infinitas relaciones y se hace posible la transformación del hombre y del mundo. Así es cómo el artista en cierta manera también crea algo nuevo, una nueva imagen en la que el poeta, el escultor, el arquitecto proyectan su yo y en la misma medida también proyectan el yo de su generación.

La poesía no es la expresión de un mundo onírico y la metáfora no es simple y llanamente una ilusión. Lo sería si el poeta fuera un mero contemplativo del paisaje, en ese caso la poesía sería el reflejo de una realidad muerta. Sin embargo, claro está, ningún artista por muy sublime que lo sea, podrá darle vida a su creación, y de esta manera el escultor jamás le dará calor humano a una de sus obras, y el pintor al efectuar un paisaje no le dará ni el más mínimo movimiento, y el poeta en sus poemas simplemente podrá recrear el mundo de las cosas a través de su lenguaje poético.

El artista tiene su mérito en cuanto nos trata de acercar al mundo de lo que es. Por lo tanto, toda obra no es la realidad en sí, porque el mundo evoluciona, vivimos en un ritmo cambiante y nada permanece estático. Pero podemos atrevernos a afirmar que en cada obra yace latente todo un mundo de circunstancias. Un mundo complejo, donde cualquier obra poética, independientemente de su tema, el lector podrá abordarla de diferentes perspectivas y de esta manera se hará una idea de lo que el poeta ha querido comunicar, aunque el lector a su vez nunca dará por agotado dicho tema, porque en cada obra siempre hay algo más.

La poesía opera sobre el extenso campo de la realidad experimentada pero no conocida del otro, o lo podemos decir de otra manera: el nervio motor en el poema es la realidad, experimentada subjetiva o colectivamente, y esto es lo que revela la poesia en si misma.

Más allá del valor estético, el poeta se vuelve portavoz de la vida misma, porque poesía lo es todo: lucha, peligro, acción y muerte. El poeta en sus poemas inmortaliza a la acción misma y aunque los poemas abandonen relativamente el espacio de su tiempo, siempre habrá en ellos algo de presente, y esto es la poesía.

Para Góngora, la poesia, en todo su rigor, es un lenguaje construido 
como un objeto enigmático. Esta forma de definir la poesia resulta un poco fría y misteriosa. El yo poético, no es tan sólo un estado anímico de quien escribe, se trata de elaborar una sintesis entre el alma que articula la palabra y la realidad a la cual se hace referencia. La palabra poética a veces no se comprende fuera de ella. El conjunto de las palabras elegidas funciona en un mundo poético que fascina, pero que no es restrictivo, cualquiera puede penetrar y experimentar la alegre sintonia de los sonidos, donde las palabras tienen su propia autonomía y si la razón humana las vacía de su contenido, las mutila y las saca de su órbita original.

El poeta en cierta manera propone un reto al lector y éste tiene que tener la suficiente sutileza para descubrir el trasfondo del poema, y para lograrlo, deciamos anteriormente, tiene que sumergirse en el ambiente de la poesía, o más bien en el mundo gravitacional de la poesía, donde tendrá que emerger con algo de ella. En la subjetividad poética se encierra un momento histórico y un tiempo que define lo que se ha determinado en la versificación o en la prosa de un poema.

Hay que evitar un subjetivismo extremo en el quehacer poético y esto es muy sencillo de comprender. Si el yo es quien simplemente se proyecta en el poema, terminará por agotarse, por corromperse, pero por otro lado si la poesía es desubjetivizada, se deshumaniza y se vuelve algo formal sin alma, sin intuición de lo que acontece y apasiona al hombre.

El poeta trabaja con elementos ya dados, existen unos criterios estructurados en un lenguaje particular, en una sociedad y en una cultura, sin embargo, el poeta es capaz de utilizar esos mismos elementos y configurarlos creativamente sin desfigurar la realidad. Con esto no queremos decir que el quehacer poético es simplemente de carácter ornamental. En cualquier actividad del hombre existe en cierta manera algo nuevo, aunque para la conciencia humana las cosas siempre están presentes, es decir, la vida cotidiana del hombre está circunscrita a la mediatez de las cosas; y sólo cuando interviene el porqué, es cuando las cosas comienzan a ser racionalizadas.

El poeta no debe ser la medida de las cosas ni del corazón humano. Sería admitir como una premisa irrefutable lo que Friedric Nietzche nos afirma: en el fondo el hombre se mira en el espejo de las cosas, considera bello todo aquello que le devuelve su imagen. En lo bello el hombre se pone a sí mismo como medida de la perfección; en casos escogidos se adora a si mismo en lo bello. Esta forma de valorar la conducta del hombre es inadmisible desde cualquier punto de vista. Seria pensar que el poeta percibe el mundo como un medio para lograr su fin, cosa absurda y a la vez estúpida, pero posible en una mente humana que padece un desequilibrio síquico, un estímulo narcisista, permisivo, pero dañino, porque deforma la realidad.

En nuestros dias todavia persisten ciertos rasgos maniqueos: el bien y el mal; lo bello y lo feo; materia y espíritu; realidad e idea; lo que existe y lo que no existe. En definitiva, se ha tratado de elaborar un des- 
tino ajeno al propio hombre, se mueven intereses mezquinos que impiden que el hombre vea las cosas tal como son, en su propio contexto y en la concatenación de su compleja realidad y ésta no debe verse como un hecho aislado, o como un fenómeno misterioso donde sólo nos queda contemplar lo que no entendemos.

Respecto al sentido de la belleza diremos que lo feo es feo porque esa es su identidad, y lo bello es bello y no puede ser feo porque entonces sería otra cosa. Y todo es bello y todo es feo, según desde la perspectiva en que se analice cada uno de los dos aspectos. El mundo físico es considerado perceptible y el hombre al percibirlo lo hace suyo y lo aprehende sensibilizándose a través de esa relación continua con el mundo.

La belleza pertenece al mundo de las cosas y el poeta a través de su estilo, va delineando un mundo que se hace palabra artísticamente elaborada. La poesía es el arte del embellecimiento donde los elementos humanos y materiales se unen para formar un mundo de imágenes que navegan en un fluir infinito. Es un desfile vertiginoso que brota de la hondura humana y la razón simplemente contempla la desnudez de la metáfora poética.

\section{La poesia y el mundo en conflicto}

Con este título quiero señalar que el mundo no es una masa amorfa, donde nada pasa y todo permanece igual.

Somos conscientes de que el mundo es un mundo en conflicto, donde el hombre apenas logra asimilar algunos de esos cambios que determinan su comportamiento y que a la vez establecen las leyes del juego. En un mundo donde la vida no es un sueño, sino que se gana o se pierde, el hombre no puede ser un extraño ni un simple espectador. Por consiguiente, el poeta no ve el mundo como una realidad excluyente de su creación poética.

"El escritor está inmerso en las circunstancias de su tiempo, pero con el ritmo propio de su vida" ${ }^{1}$. O, digámoslo de una manera más general: "Todos estamos comprometidos con nuestro tiempo; y el que no lo está es que ha renunciado a ser hombre, a sentirse como tal. Quien se evade de los sufrimientos, de los quebraderos, de las dificultades de su hora, si tiene poder para elevarlos a la preocupación general y para encauzarlos hacia el logro de una solución adecuada y no lo hace, es un insolidario, un antisocial" 2 .

El poeta no vive en un mundo reducido a la intimidad de su ego. Como hombre es un producto histórico-social, político-económico. El hombre-poeta está ubicado en el espacio y en el tiempo. La vida no está

1. APARICIO LóPez, T., 20 novelistas españoles contemporáneos, Estudio Agustiniano, Valladolid 1979, 191.

2. Ibid., 191. 
formada por saltos históricos, no existen hechos espontáneos; hay una continuidad y una intima relación dentro del macromundo en que vivimos. Nada permanece anclado. El destino del hombre se forja y evoluciona en función de un todo. La vida es siempre posibilidad y en ella todo adquiere sentido, hasta lo más cotidiano, lo circunstancial, posee un valor.

Para el poeta hacer poesía significa ser penetrado por la dialéctica intramundana. La idea y la acción debe ser un quehacer continuo, por medio del cual el poeta toma conciencia de sí mismo y a la vez guarda la pertinente distancia frente a los acontecimientos. El poeta es el hombre que se debe a todos, por eso la poesía es universal. Sin embargo, el arte poético no debe ser vendido a intereses mezquinos. Aunque en la vida esto muy a menudo sucede. Existen hombres que ponen su pluma al servicio del mejor postor, o lo que es peor aún, la utilizan para adquirir un maldito peldaño en el maquavélico destino en el que danzan los operadores.

La realidad como totalidad organizada del mundo impone a la palabra del poeta el momento determinante de la acción y ésta puede ser abordada de diferentes maneras. Por lo tanto el hombre puede pasarse toda su vida contemplando al mundo y lo que contiene o puede asumir una actitud más positiva, iniciando un proceso de cambio. Las relaciones hombre y mundo pueden convertirse en fuerzas generadoras, capaces de revolucionar todo lo existente. En base a estas ideas afirmamos lo siguiente: la poesia al convertirse en poema se convierte en una obra inerte, sin embargo, no podemos concluir precipitadamente diciendo que la poesía es la razón velada de la realidad. Definitivamente rechazamos cualquier consideración que se nos haga en este sentido.

El poeta no debe ser un instrumento de nadie y aun cuando somos conscientes que los acontecimientos históricos ejercen una influencia determinante en la conciencia del hombre, no por eso el hacer poesía tiene que estar condicionado a criterios arbitrarios o sometido a un poder hegemónico.

El contenido de la realidad se conceptualiza a través de las ideas y en poesia la metáfora comunica algo más que la simple forma en que está enunciada la prosa o el verso poético. La poesía es una de las maneras más fáciles y bellas por medio de la cual el hombre desnuda su existencia, pero a la vez es la labor más dificil porque se trata de ser fiel a la realidad, y quien no lo hace se traiciona a si mismo y encubre la ręalidad que tarde o temprano será descubierta.

La poesía es magia, pero una magia donde todo lo que existe adquiere su sentido y tiene su valor que no es negociable. El amor es una de esas palabras mágicas donde converge el quehacer poético, y tiene una fuerza autónoma que recrea todo lo que se relaciona con ella.

Una última intuición nos lleva a exclamar: el poeta nunca ofrece la totalidad de la realidad, por lo tanto, la poesia es unilateral, no globalizante.

En el quehacer poético siempre hay que estar creando nuevas for- 
mas, nuevos giros. En el mundo en conflicto la poesía también es conflictiva.

\section{Lo cotidiano entre la razón y la fantasía}

Se ha dicho que en el mundo dejarán de existir poetas, pero no la poesia. Ésta es algo inherente a la naturaleza humana. En la reflexión anterior afirmábamos que la poesia se hace en la historia y a la vez hace historia.

La vida del hombre y sus circunstancias múltiples son materia prima para el quehacer poético y éste siempre es infinito. En el mundo y en el universo insondable, existe poesia; un submundo que emerge en las expresiones del arte y ofrece al hombre un panorama de contemplación plena, donde los sentidos y la imaginación vuelan, libres, llevando un mensaje que se propaga en la convergencia cultural de un pueblo. Todo esto que expresamos es sin embargo, el polo opuesto de una realidad que aprisiona y ensombrece el arte poético. Ayer la razón convertida en amo y señor de la causa eficiente, origen de todo lo que existe, proponia las reglas del juego, y subordinaba los sentidos y otros aspectos humanos a un grado inferior y carente de importancia. Marcuse haciendo alusión a la época clásica del racionalismo y concretamente refiriéndose a Kant nos hace el siguiente comentario: "De acuerdo con el concepto represivo de la razón, el conocimiento llegó a ser la preocupación última de las facultades superiores, no sensuales, de la mente; la estética fue absorbida por la lógica y la metafisica. La sensualidad, como la facultad inferior e inclusive la más inferior, proporcionaba cuando más la materia prima, el material crudo, para el conocimiento, para que éste fuera organizado por las facultades altas del intelecto. El contenido y la validez de la función estética fueron disminuidos" 3 .

La fantasia era siempre síntoma de demencia, una degeneración de la realidad y por consiguiente la negación de la verdad misma. La filosofia en el devenir de las transformaciones posibles que engendra la materia va evaluando sus antiguos planteamientos y elabora un conocimiento más acorde con la realidad conocida.

La fantasía es siempre elemento de contradicción frente al juez implacable de la razón; surgen desacuerdos y en la mayoría de las veces se producen planteamientos dualistas que desequilibran la unidad inseparable que existe entre el hombre-mundo. Un hombre que conoce y sabe, este hombre hace posible la civilización, es cultura, es verdad, institución, leyes, costumbres. Todo adquiere un nuevo sentido cuando el hombre se apropia de la realidad y la hace razón de su existencia. El cientifico desnuda la realidad y se introduce en ella arriesgándolo todo, intuye, analiza, observa, imagina creativamente y a cada paso cuando quiere demarcar su campo de acción emerge la duda. Por lo tanto, cono-

3. Marcuse, H., Eros y Civilización, Seix Barral, Barcelona 1968, 171. 
cer es señalar aciertos y negaciones. Sin embargo, la realidad se puede expresar de muchas maneras, ya sea contemplándola tal como la vemos secularmente y hacemos de ella un objeto de admiración; o formulamos leyes que en base a la observación determinan algunos de sus aspectos o a través de la estética reproduciéndola creativamente.

"La verdad del arte es la liberalización de la sensualidad mediante su reconciliación con la razón" " . Se trata de ofrecer un mundo con alma, es decir, rechazamos un mundo fosilizado, impermeable, dogmático, sacrificado unilateralmente a propósitos materialistas, y un mundo sin alma sería como contemplar la muerte misma.

La materia es un mundo de sensaciones, el científico la investiga, el historiador y el antropólogo persiguen la evolución de sus acontecimientos y el artista crea los caminos y ensancha el horizonte de las posibilidades, donde hace surgir una fuente inagotable: La imaginación es como el agua fresca, nos calma la sed, pero no podemos prescindir de ella. La imaginación es posibilidad real. El ser humano no tiene por qué reprimir sus emociones, ha nacido para remontarse hacia lo infinito $y$ no para vivir cobardemente arrinconada en las llanuras. "La imaginación llega a estar de acuerdo con las nociones cognoscitivas de la comprensión, y este acuerdo establece una armonia de las facultades mentales que es la respuesta placentera a la libre armonía del objeto estético. El orden de la belleza es el resultado del orden que gobierna el juego de la imaginación" 5 .

En nuestros días nos enfrentamos a un problema mucho más profundo que el racionalismo frio. La ciencia ha creado un monstruo y no existe en el mundo una jaula capaz de albergarlo, está en todas partes, todo lo invade y lo destruye, transforma las cosas en algo trivial o las cuantifica desvalorizándolas. Es todo un imperialismo.

La sociedad capitalista-consumista ha hecho de la técnica un instrumento capaz de monopolizar todo lo que está a su alcance. La ciencia en las manos capitalistas no se contenta con indagar la realidad, sino que quiere también utilizarla para imponer las reglas del juego, donde la conciencia humana se ve disminuida a ser simplemente un objeto de su consumo. La originaidad se destruye en la multiplicación de los objetos y el arte y la imaginación pasan a ocupar un papel secundario. La sociedad tecnocrática es masificadora, deshumanizante. Todo el entorno humano se ve invadido por objetos prefabricados, mercancía que simula el arte, pero que carece del valor único que proviene del yo humano. La máquina reproduce, el hombre crea y en cada una de sus obras se contempla su yo. Cada obra proyecta, irradia vida, dice algo, comunica al hombre con el hombre mismo. Es toda una realidad socializante. La máquina, la técnica se contempla a sí misma, narcisistamente. Es una obra muerta, cuantificada para el consumo vulgar que urge en el hombre

4. Ibid., 174.

5. Ibid., 169. 
necesidades no cualificadas en el orden lógico de la razón. El arte muere de inanición en la conciencia mecanizada. El hombre ha dejado de ser libre y ha vendido su alma a una sociedad que cada día le va narcotizando en dosis letales. Por las calles de nuestras metrópolis observamos muertos ambulantes y las grandes cadenas comerciales son tumbas abiertas, donde se inhala el vacío de una cultura. $Y$ en los rótulos propagandistas absurdamente leemos: "alludit tibi vitae prosperitas", la felicidad te sonrie.

En nuestros días nos enfrentamos a una de las amenazas jamás soñadas: el poder económico lo compra todo, hasta lo más intimo y fundamental en el hombre, su conciencia. Por lo tanto es un deber luchar por una condición humana que esté más allá de la necesidad y la compulsión externa, hay que expresarnos sin miedos, sin prejuicios. Si esto lo logramos obtendremos nuestra libertad y con ella haremos la revolución definitiva, por medio de la cual el hombre se va a imponer en el corazón mismo del sistema dominante, entablando nuevas relaciones más justas y menos ultrajantes. Será una realidad libre, con hombres libres, homo novus, y la alegría volverá a resurgir en todos los enajenados, los que han vivido en una densa atmósfera arbitraria, llamada Capitalismo dominante o lo que es lo mismo, la entronización del infierno.

Una nueva imagen del mundo en que soñamos (donde el hombre y su realidad circundante no son polos opuestos) la podemos describir con estos términos: "La naturaleza, el mundo objetivo, será experimentada entonces primariamente, ni dominando al hombre (como en la sociedad primitiva) ni siendo dominada por él (como en la civilización establecida), sino más bien como un objeto de contemplación. Con este cambio en la experiencia básica y formativa, el mismo objeto de experiencia cambia: liberada de la explotación violenta y de la dominación y configurada en su lugar por el impulso del juego, la naturaleza será liberada también de su propia brutalidad y llegará a ser libre para desplegar las riquezas de sus formas sin propósito, que expresan la vida interior de sus objetos" 6 . A través de la lectura de esta cita de Marcuse, podemos darnos cuenta que en un mundo desalienado es posible que los hombres continúen imaginando creativamente, sin dejarse instalar por un sistema de vida donde no es posible la estética, el arte, la poesía.

No importa que los acontecimientos cambien y surjan nuevos sentimientos. Esto es posible y todos sabemos que la vida, la individualidad del hombre está sujeta a variaciones, pero de lo que estamos seguros es que la "imaginación preserva a los objetos de aquellos procesos mentales que han permanecido libres del principio represivo de la realidad en su función estética, éstos pueden ser incorporados a la racionalidad consciente de la civilización madura" ${ }^{7}$.

6. Ibid., 179 .

7. Ibid., 182 . 


\section{La Cultura y el Arte de escribir para el pueblo}

El mundo ha ido evolucionando a pasos gigantescos, de tal manera que una simple noticia recorre hoy el mundo en unos cuantos minutos. Cada vez el hombre se vuelve más mundo, es decir, que las ideas hoy están por todas partes y en las ideas viaja el hombre. Digamos que el hombre ha salido del ostracismo primitivo en que estaba sumido y el tipo de hombre actual es más globalizante y universal.

Comparativamente hablando el hombre de hace unos años atrás es hoy la suma de todos los hombres en proyección continua. El hombre inaugura hoy un mundo secularizado, más autónomo, menos misterioso y menos abstracto. Es el mundo transformado por el conjunto de fuerzas humanas. El pasado y el futuro confluyen en un eterno presente.

La civilización actual ha impuesto nuevos moldes culturales; el concepto romanticista sobre la realidad intramundana es hoy un elemento marginal. Todo se mide con el rasero colectivizante, el individuo no se entiende si no es en los otros. El yo y el tú son la negación del grupo, por lo tanto, el yo y el tú para lograr su sobrevivencia tienen que diluirse en la colectividad.

Hoy en dia existen menos necesidades insatisfechas, los individuos poseen a su alcance los recursos materiales e intelectuales suficientes para influir de una manera efectiva en la coordenada social e histórica de su tiempo. Podríamos enumerar una cantidad infinita de los alcances logrados por la civilización actual, pero sería desviarnos del tema que nos hemos propuesto y nuestra finalidad es señalar unas cuantas pistas que nos pueden ayudar a comprender no el desnudo vértice del iceberg, sino el resto del que subyace en la traumática incomprensión humana.

La cultura siempre se ha caracterizado por ser el manjar exclusivo de la clase dominante y todos sabemos que un pueblo ignorante es ignorado por aquellos que detentan el poder.

Durante mucho tiempo el objetivo del arte ha sido la utilización de un lenguaje y símbolos que a través de cierta sutileza y eficacia han venido manipulando las fuerzas dominantes para eternizar un sistema donde sus intereses estén siempre protegidos y fuera del alcance de las minorias que en otras palabras son las mayorias, es decir, el pueblo adormecido con expresiones contaminadas y que aseguran el control absoluto por medio del encantamiento mágico de los sentidos humanos. En un sistema así, el valor simbólico de las cosas pierden interés en el individuo y sólo es interpretado por la clase escogida, una clase mesiánica que prodiga de vez en cuando cierta simulación del arte para que el pueblo siga viviendo atrás del umbral de la vida.

Se da una depauperación progresiva en cuanto al concepto popular del arte. Para el pueblo, la pintura, la escultura, los libros, el teatro, los museos, la poesia misma, son algo ininteligibles, son sitios y cosas que sólo las entienden determinadas personas. Para el hombre de la calle el arte es algo que no tiene tiempo ni espacio. La cultura actual es masificadora pero no socializante, no da tiempo a la crítica, pues estamos amenazados siempre de lo nuevo, lo nuevo, siempre lo nuevo. 
Es urgente llevar a efecto una colectivización del arte en todas sus expresiones; no debe seguir siendo una materia cruda que transforma y comprende el genio.

Elevar el nivel cultural de los pueblos, es devolver lo que les pertenece, lo que les ha sido arrebatado injustamente.

Al difundir la cultura no se trata de repartir un caudal ilimitado de expresiones artísticas o conceptos que en la lógica del pueblo no se entienden; por lo tanto, de lo que se trata es de hacer cultura con el pueblo; la cultura nace en el corazón mismo de los pueblos y el pueblo lo que necesita son instrumentos espirituales que ayuden a despertar y acrecentar a la vez lo que ya existe en el sustrato social de una estructura humana. Recordemos que el pueblo en sí mismo es cultura. Por lo tanto, no debemos imponer conceptos ajenos a nuestros pueblos, aunque no somos ilusos.

Actualmente los individuos consumen sin reservas, aceptan patrones que le son impuestos a través de una sociedad mercantilista.

La cultura contemporánea se caracteriza por ser algo fugaz, carente de solidez alguna. Todo está prefabricado y vivimos a la espectativa del próximo invento; es una patologia que rebasa la voluntad del hombre, disminuye su capacidad receptiva y todo lo da por supuesto; no existe o se ha vuelto algo marginal el esfuerzo creador, estamos debilitados y el cansancio nos impide formar un frente de lucha.

La enseñanza en nuestros centros educativos debe ser una realidad asimilable. El mundo de las letras debe representar a una sociedad dinámica, integrada y progresista. En cuanto se refiere al Estado, éste no debe nunca eludir su deber como conductor de las fuerzas creativas del pueblo. El Estado más que una estructura burocrática y con carácter imperativo, debe ser un animador de la cultura, teniendo en cuenta que cada individuo es importante y que a la vez el conjunto de individuos enriquecen el caudal cultural que posee un pueblo.

Existe una obligación moral y material en nuestro tiempo y es la de despertar la conciencia humana para que logre su autonomia. Es un reto histórico donde los hombres deben hermanar sus culturas y hacer del mundo un mundo más civilizado, más humano y con mayor respeto a la realidad objetiva, circundante. Recordemos que el hombre tiene como punto de referencia al mundo mismo y sin él sería un satélite sin órbita, suspendido en el vacio.

El hombre del mañana, todavía no existe, es un proyecto humano inacabable y aunque el hombre siga determinando su futuro, por su misma naturaleza, no es una realidad finalizada.

El hombre todavía sigue hipotecando su destino a fuerzas dominantes, hegemónicas; el predominio del factor económico es la medida de todo lo que existe y se prolonga más allá de la muerte. Hoy no se lucha contra un individuo económicamente establecido, sino contra todo un sistema que condiciona la conducta humana. Así es que ante este panorama ensombrecido, la cultura tiene que pasar por un proceso depura- 
dor y el escritor de nuestros dias se enfrenta a una gran responsabilidad a la hora de hacer su contribución a la cultura.

El escritor tiene que saberse situado como los demás hombres de su tiempo, su libertad por lo tanto, siempre estará en tensión. En medio de los limites que la sociedad le impone, debe ser creativo, la idea que inventa debe formularla de tal manera que llegue al pueblo. El escritor debe entregarse totalmente a la llamada urgente de la libertad que exigen los demás hombres. Nunca se debe ofrecer una verdad parcial y aislada, seria un error imperdonable. El objeto representado a través de las ideas debe estar liberado de todo lo que lo deforma y lo aliena; en definitiva debe ser revelado en la pura desnudez de su existencia.

"Escribir para el pueblo, es por de pronto, escribir para el hombre de nuestra raza, de nuestra tierra, de nuestra habla, tres cosas de inagotable contenido que no acabamos nunca de conocer. $Y$ es mucho más, porque escribir para el pueblo nos obliga a rebasar las fronteras de nuestra patria; escribir también para los hombres de otras razas, de otras tierras y de otras lenguas" 8

La literatura de nuestro tiempo debe tomar conciencia de su autonomia, no debe someterse a poder temporal alguno ni empeñar sus ideas a una ideologia totalitaria. El escribir tiene que superar el mundo de la servidumbre. Una obra escrita, si no es contrastada con la realidad se vuelve algo abstracto, lejos de la esencia vital que es la realidad misma.

La literatura es y será siempre la expresión subjetiva, producto en permanente evolución que tiene su origen y su destino en el hombre mismo.

Es difícil imaginarnos una sociedad sin clases, donde el acto de escribir sea una realidad cotidiana del hombre común; el medio que estará al alcance de todos para ofrecer las ideas a un pueblo ávido de material reflexivo. Seria una sociedad sin clases donde la dialéctica del buen juicio dominará por completo cualquier actitud arbitraria que emergiera en contra del bien común. Sólo en una sociedad sin clases es posible que el escritor presente una obra sin mutilaciones, sin censuras que condicionan la palabra y la mediatizan; la división de la sociedad deforma la obra con una escisión entre el mundo y el hombre como dos realidades opuestas, polarizadas.

La literatura, las artes y cualquier otra expresión cultural tiene como tema primordial al hombre y su mundo; lo concreto en la totalidad humana. De alli deducimos que hay que espiritualizar al mundo y esto se logra destruyendo las sombras que mitifican el orden natural de las cosas.

El escritor toma del mundo lo cotidiano, lo ordinario, lo que es y no puede. ser deformado. En cierta manera escribir es siempre tratar de ha-

8. Machado, A., Antología de su prosa, I, Cultura y Sociedad (Aurora de Albornoz), Madrid $1970,220$. 
cer una sintesis relativa del hombre y del mundo; y el hombre y el mundo serán siempre un valor supremo, impuesto no por una conciencia arbitraria, misteriosa, sino como un valor que lo es en sí mismo, simplemente porque existe.

En la literatura hay que expresar siempre las tensiones humanas, las luchas y esperanzas de los pueblos. La vida no es algo predeterminado, en ella hay un continuo movimiento que envuelve al hombre y a su mundo, y en cierta manera hablar del hombre y del mundo es siempre hablar del porvenir del hombre. Todas las cosas son atraidas por una fuerza centrifuga que tiene como núcleo al hombre mismo. Por lo tanto, se trata de concientizar al hombre para que el mundo sobreviva. Sin la madurez de la razón humana, todo se vuelve una actividad formal, imprecisa e idealizante. El hombre no debe contemplar sus ideas como el mundo eterno platónico; el hombre debe adentrarse en su yo y descubrir en su intimidad aquellos valores que le hacen más humano, y a la vez rechazar lo que no es digno de permanecer en él.

Un hombre libre es la voz de las mayorías, nunca una individualidad. Al fin podemos simplificar diciendo: el hombre es lo que es por ser con los demás. Lo que soy lo debo a mis esfuerzos y a los demás hombres que han hecho posible que yo sea. "Ser libre. Ser causa de sí, poder decir: yo soy porque yo lo quiero. Ser mi propio comienzo" ${ }^{9}$., pero dentro de la. existencia comunitaria.

Lo individual humano, el yo exclusivamente lo es entre la diferencia no absoluta de hombre a hombre, porque el pensamiento y los demás actos volitivos son patrimonio de lo humano, no de lo individual. El modo de vivir, de razonar, de responder a la realidad es un acto individual, pero no excluyente de los otros actos volitivos que se dan en otros hombres.

La cultura lentamente va adquiriendo un matiz más universal y asume una expresión más dinámica. Los pueblos están en una continua asimilación de todos los valores que van surgiendo a través del tiempo, y un volver a lo temporal, significa que los hombres de ayer están presentes en el hoy de nuestra historia. Los hombres desaparecen, pero subsisten en las reivindicaciones de los otros hombres, los que están fuera de un presente superado. De tal manera que aunque a simple vista prevalezcan nuestros patrones culturales, sin embargo, la base de la cultura actual es un patrimonio del pasado. La cultura en el devenir histórico adquiere un carácter universal. Somos productos de una cultu-ra, de un tiempo al cual responde nuestra manera de ser, pero a la vez la cultura rebasa la particularidad de un cuadrante histórico y por eso el hombre es cósmico, es mundo, el porqué de su existencia está en la génesis del mundo mismo. La heterogeneidad es lo que hace grande al hombre, en ella reside la riqueza humana.

9 SARTRE, J.P., Los caminos de la libertad, 1. La edad de la razón, Alianza, S.A., Madrid 1983, 67. 
Hay que percibir al mundo no como algo ajeno al quehacer humano. El pensamiento, la palabra es la representación de la realidad, podemos decir con cierta naturalidad que las ideas son el lenguaje de la materialidad intramundana. El escritor tiene una veta inagotable en la extensión del mundo, éste se nos brinda gratuitamente, pero a la vez no se deja poseer del todo. Así avanza la ciencia y así por consiguiente, hay material abundante para que el artista, el escritor, consuma las horas de su vida, no en la contemplación mística del mundo, sino en su transformación.

Los escritores no tienen por qué satisfacer en una forma absoluta al lector, éste debe utilizar sus capacidades que están a su alcance para reelaborar cada obra; tiene que hacer un proceso digestivo de las ideas que consume, y en cierta manera lo que hace es una reinterpretación del hombre y del mundo. El lector como sujeto pensante amplifica y condiciona la obra del escritor.

Las ideas deben ser integradas a la condición existencial de los hombres; si las ideas se conciben separadas de la realidad, estamos negando a la realidad misma y entramos en una contradicción, donde el hombre todopoderoso refleja su propio yo; o en un sentido más amplio, es el estado dominante (política y económicamente) el reflejo de la realidad y ésta se manifiesta en la degradación del hombre y en la desigualdad secular en que todavia permanecen muchos pueblos.

En las relaciones continuas de hombre y mundo debe haber una gran responsabilidad. Aprehender el mundo y lo que en él se contiene significa un desgarramiento de nuestro yo y un esfuerzo por asumir su influencia determinante. El mundo me condiciona y sin él no hay alternativa para mi vida, y muchas veces la limitación en el hombre es causa de sufrimiento; entre el hombre y el mundo se ejerce una acción directa y a la vez mutua. Es una cadena de interrelaciones permanentes. Sartre dice que "el hombre es un ser del mismo tipo que el mundo", "novedad irreductible, noción empírica". Todo tiene un sentido en el mundo y ser en el mundo significa tomar conciencia de nuestro propio destino. Somos hombres, pueblo, cultura en un mundo cada vez más civilizado, donde la razón y los sentimientos se conjugan en armonía dialógica. La democratización de la palabra es posibilidad humana. En el próximo siglo la cultura estará determinada por los intereses de los individuos libres.

Wigfredo TERCERO REYES

Estudio Teológico Agustiniano

Valladolid 